\title{
Radiosensitization by Gold Nanoparticles: Impact of the Size, Dose Rate, and Photon Energy
}

\author{
Kirill V. Morozov 1,2, Maria A. Kolyvanova 1,3, Maria E. Kartseva ${ }^{4}$, Elena M. Shishmakova ${ }^{4}$, \\ Olga V. Dement'eva ${ }^{4}$, Alexandra K. Isagulieva ${ }^{1,5}{ }^{(D}$, Magomet H. Salpagarov ${ }^{1}$, \\ Alexandr V. Belousov ${ }^{1}{ }^{1}$, Victor M. Rudoy ${ }^{4}$, Alexander A. Shtil ${ }^{1,6}{ }^{,}$Alexander S. Samoylov ${ }^{1}$ and \\ Vladimir N. Morozov 1,3,*这 \\ 1 State Research Center-Burnasyan Federal Medical Biophysical Center of Federal Medical Biological Agency, \\ 123098 Moscow, Russia; morozov.kv15@physics.msu.ru (K.V.M.); kolyvanova@physics.msu.ru (M.A.K.); \\ kia2303@yandex.ru (A.K.I.); magometonco@mail.ru (M.H.S.); belousovav@physics.msu.ru (A.V.B.); \\ shtilaa@yahoo.com (A.A.S.); asamoilov@fmbcfmba.ru (A.S.S.) \\ 2 Department of Physics, Lomonosov Moscow State University, 119234 Moscow, Russia \\ 3 Emanuel Institute of Biochemical Physics, Russian Academy of Sciences, 119334 Moscow, Russia \\ 4 Frumkin Institute of Physical Chemistry and Electrochemistry, Russian Academy of Sciences, \\ 119071 Moscow, Russia; maryakar@mail.ru (M.E.K.); alena_shishmakova@mail.ru (E.M.S.); \\ redmoun@mail.ru (O.V.D.); dema_ol@mail.ru (V.M.R.) \\ 5 Gause Institute of New Antibiotics, 119021 Moscow, Russia \\ 6 Blokhin National Medical Research Center of Oncology, 115478 Moscow, Russia \\ * Correspondence: morozov.v.n@mail.ru; Tel.: +7-985-117-36-03
}

Received: 4 April 2020; Accepted: 9 May 2020; Published: 17 May 2020

\begin{abstract}
Gold nanoparticles (GNPs) emerged as promising antitumor radiosensitizers. However, the complex dependence of GNPs radiosensitization on the irradiation conditions remains unclear. In the present study, we investigated the impacts of the dose rate and photon energy on damage of the pBR322 plasmid DNA exposed to X-rays in the presence of $12 \mathrm{~nm}, 15 \mathrm{~nm}, 21 \mathrm{~nm}$, and $26 \mathrm{~nm}$ GNPs. The greatest radiosensitization was observed for $26 \mathrm{~nm}$ GNPs. The sensitizer enhancement ratio (SER) $2.74 \pm 0.61$ was observed at $200 \mathrm{kVp}$ with $2.4 \mathrm{mg} / \mathrm{mL}$ GNPs. Reduction of X-ray tube voltage to 150 and $100 \mathrm{kVp}$ led to a smaller effect. We demonstrate for the first time that the change of the dose rate differentially influences on radiosensitization by GNPs of various sizes. For $12 \mathrm{~nm}$, an increase in the dose rate from 0.2 to $2.1 \mathrm{~Gy} / \mathrm{min}$ led to a $\sim 1.13$-fold increase in radiosensitization. No differences in the effect of $15 \mathrm{~nm}$ GNPs was found within the 0.85-2.1 Gy/min range. For $21 \mathrm{~nm}$ and $26 \mathrm{~nm}$ GNPs, an enhanced radiosensitization was observed along with the decreased dose rate from 2.1 to $0.2 \mathrm{~Gy} / \mathrm{min}$. Thus, GNPs are an effective tool for increasing the efficacy of orthovoltage $\mathrm{X}$-ray exposure. However, careful selection of irradiation conditions is a key prerequisite for optimal radiosensitization efficacy.
\end{abstract}

Keywords: radiosensitizers; gold nanoparticles; X-ray; dose rate; plasmid DNA; radiotherapy

\section{Introduction}

The ability of certain chemical compounds to enhance the biological effect of ionizing radiation had long been known [1]. However, the search for new radio modifiers for radiation therapy (RT) remains important [2-4]. Nanoparticles (NPs) of metals with the high atomic number (Z) are a new promising class of antitumor radiosensitizers both for classic photon and particle RT [5-8]. Gold nanoparticles (GNPs) are particularly attractive since they increase the efficacy of ionizing radiation in various biological systems including molecular solutions [9,10], cell-based models [11,12], and in vivo [13,14]. 
The shape and the size of GNPs as well as their surface properties may vary widely [15-17]. This diversity allows for design of GNPs potentially applicable in RT of various tumors. On the other hand, since the cornerstone of RT is the accuracy of dose delivery and treatment predictability, it is exceptionally important to identify the most efficient regimens of irradiation in the presence of GNPs. However, nano-radiosensitizers are rather delicate systems. Even minor changes in their characteristics may affect their interaction with cells $[18,19]$ as well as the physicochemical aspects of radiosensitization [20-26] ultimately leading to significant differences in the magnitude of the effect of NPs [27-30].

In addition to the rational design of GNPs, a key factor is the selection of optimal irradiation conditions that provide the required efficacy of radiosensitization. Different photon sources (X-ray therapy machines, electron accelerators, and brachytherapy sources) with the energy range of $30 \mathrm{keV}-25 \mathrm{MeV}$ are widely used in the clinic. Although GNPs exhibit radiosensitization in combination with many photon sources [31], the efficacy significantly depends on the radiation energy and its spectral composition [9,32-34]. Even in the case of synchrotron exposure, the dependence of GNPs' radiosensitization effect on radiation energy is not completely clear $[35,36]$.

These considerations justified the search for optimal irradiation parameters that would provide the maximum radiosensitization effect of spherical GNPs with a given size and surface chemistry. We exposed the pBR322 plasmid to X-ray photons as a model of radiation-induced DNA damage. The dependence GNPs' radiosensitization efficacy on the conditions of irradiation was studied by varying the dose rate and voltage on the $\mathrm{X}$-ray tube. To evaluate the radio-sensitizing efficacy, the values of the sensitizer enhancement ratio (SER), mono-dose enhancement factor (EF), and physical dose enhancement factor (DEF) were calculated.

\section{Materials and Methods}

To synthesize GNPs, we used chloroauric acid trihydrate ( $\geq 99 \%$, Acros Organics, Geel, Belgium) and sodium citrate (99\%, Sigma-Aldrich, St. Louis, MO, USA). Distilled water additionally deionized with an Arium 611 purification system (Sartorius, Göttingen, Germany) was used as a solvent. Spherical GNPs were synthesized according to a multi-step protocol [37]. First, the seed NPs (Sample 1) were obtained by injecting a solution of $\mathrm{HAuCl}_{4}(1 \mathrm{~mL}, 25 \mathrm{mM})$ into the boiling solution of sodium citrate $(150 \mathrm{~mL}, 2.2 \mathrm{mM})$ under vigorous stirring. After boiling for $10 \mathrm{~min}$, the reaction system was cooled down to $90^{\circ} \mathrm{C}$, and the stepwise growth of Au seeds was carried out. In so doing, two portions of $\mathrm{HAuCl}_{4}$ solution $(1 \mathrm{~mL}, 25 \mathrm{mM}$ ) were injected into the system $30 \mathrm{~min}$ apart. The obtained dispersion (Sample 2) was diluted by replacing $55 \mathrm{~mL}$ of its volume by the same volume of $2.2 \mathrm{mM}$ sodium citrate. This two-step procedure of seed growth was repeated twice and yielded sample 3 and sample 4 , respectively.

The size of GNPs was determined using a Technai G2 F-20 S-Twin TMP (FEI, Eindhoven, Netherlands) high-resolution transmission electron microscope (HRTEM) operating at an accelerating voltage of $200 \mathrm{kV}$. A droplet of aqueous GNP dispersion was placed onto a formvar-coated copper grid, exposed on air for $1 \mathrm{~min}$, and then removed with the filter paper. HRTEM images were processed using Image software (National Institutes of Health, Bethesda, MD, USA). In some cases, a Zetasizer Nano ZS dynamic light scattering (DLS) spectrometer (Malvern Panalytical, Malvern, United Kingdom) was used to determine the size of GNPs. The results obtained by HRTEM and DLS techniques were in good agreement.

Extinction spectra of Samples 1-4 were recorded on an Evolution 300 double-beam spectrophotometer (Thermo Electron Corp., Waltham, MA, USA) at the wavelength range of 250-800 nm.

The concentration of metal $\mathrm{Au}, C_{\mathrm{Au} 0}$, in the dispersion was estimated by the formula below [38].

$$
C_{\mathrm{Au} 0}=0.355 D_{390}
$$


where $D_{390}$ is the optical density of dispersion at $390 \mathrm{~nm}$, corresponding to the region of Au inter-band transitions. Its value is determined only by the concentration of metal $\left(C_{\mathrm{Au} 0}\right)$ and does not depend on the particle size and shape.

Figure 1 shows typical HRTEM images of GNPs. The prepared particles show narrow size distributions. Their main characteristics are given in Table 1.
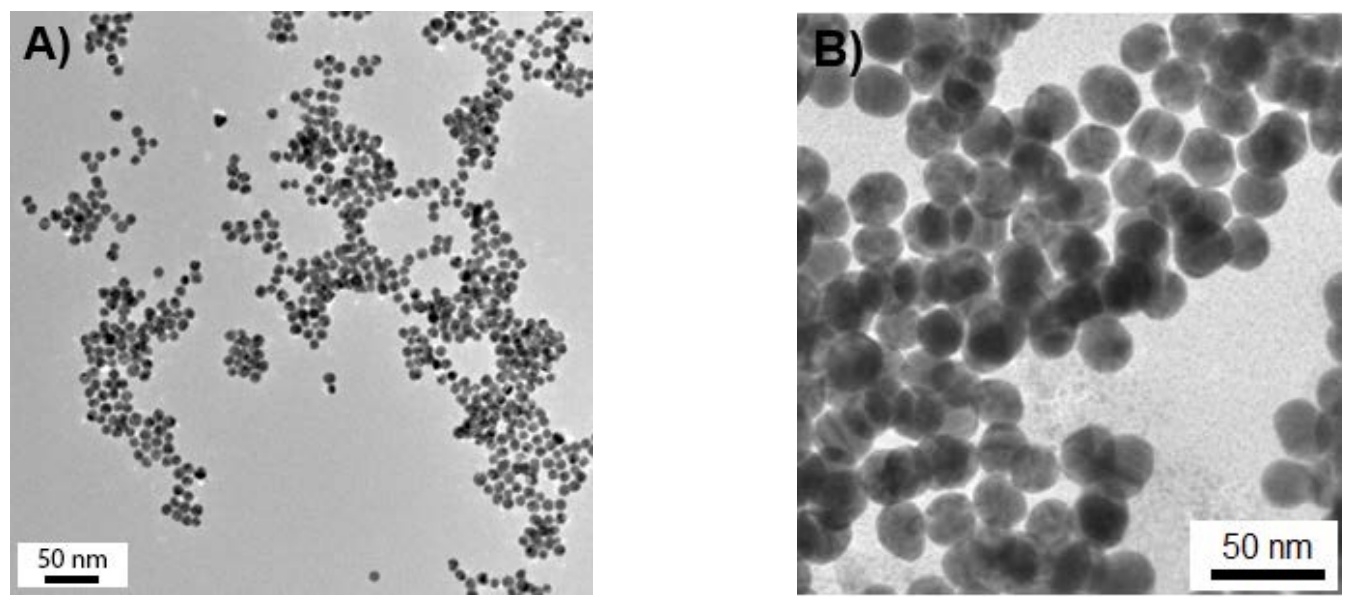

Figure 1. High-resolution transmission electron microscope (HRTEM) images of (A) sample 1 and (B) sample 4 of the prepared gold nanoparticles (GNPs).

Table 1. Characteristics of gold nanoparticle (GNP) dispersions $\left(C_{\mathrm{Au} 0}=3 \mathrm{mg} / \mathrm{mL}\right)$.

\begin{tabular}{cccc}
\hline Sample & GNP Diameter, $\mathbf{n m}$ & [GNP], $\mathbf{n M}$ & [GNP], $\mathbf{~ m L}^{\mathbf{- 1}}$ \\
\hline 1 & $12.0 \pm 0.5$ & 280 & $1.7 \times 10^{14}$ \\
2 & $14.9 \pm 0.8$ & 146 & $8.8 \times 10^{13}$ \\
3 & $21.0 \pm 1.2$ & 52 & $3.1 \times 10^{13}$ \\
4 & $26.2 \pm 2.0$ & 27 & $1.6 \times 10^{13}$ \\
\hline
\end{tabular}

The number concentration of particles (i.e., [GNP]) was calculated by dividing $C_{A u 0}$ by the mass of one GNP that was estimated from the average diameter of GNPs and the density of bulk Au. For the convenience of comparing our data with the other literature date, the [GNP] values are given in $\mathrm{nM}$ and $\mathrm{mL}^{-1}$.

For experiments with the plasmid DNA, the dispersions of GNPs were concentrated by the following procedure. GNPs were precipitated by centrifugation (Hettich universal 320R centrifuge, Tuttlingen, Germany), and the supernatant was partly decanted to reach gold content $3 \mathrm{mg} / \mathrm{mL}$ (see Table 1). The precipitate was re-dispersed in the remaining volume of the supernatant using an ultrasonic bath. Aqueous solutions $(25 \mu \mathrm{L}, \mathrm{pH}=6.9-7.1)$ of pBR322 plasmid (4361 bp; Invitrogen, Waltham, MA, USA) were prepared in $0.5 \mathrm{~mL}$ polypropylene tubes (Eppendorf, Hamburg, Germany). DNA concentration was $0.04 \mathrm{mg} / \mathrm{mL}$. The concentrations of GNPs ranged from $0.6 \mathrm{mg} / \mathrm{mL}$ to $2.4 \mathrm{mg} / \mathrm{mL}$ (three samples were used in each experiment). The binding of GNPs to DNA is a rather fast process [39]. Our preliminary experiments showed that the magnitude of radiosensitization did not depend on the incubation time within 5-120 min range (data not shown). Therefore, GNPs and DNA were co-incubated $30 \mathrm{~min}$ at room temperature prior to irradiation.

Irradiation was carried out on a RUST-M1 X-ray machine (Diagnostika-M, Moscow, Russia). The scheme of exposure is shown in Figure 2A. Radiation was generated by two simultaneously operating X-ray tubes RAP 220-5. The voltage on the X-ray tubes was 100, 150, or $200 \mathrm{kVp}$. In addition, $1.5 \mathrm{~mm}$ Al filter was used. The dose rate was $0.2-2.1 \mathrm{~Gy} / \mathrm{min}$. The exposed doses were $0-40 \mathrm{~Gy}$ with a 5 Gy increment. X-ray spectra calculated by the Monte-Carlo method using a Geant4 toolkit [40] are 
shown in Figure 2B. A detailed description of the methodology for calculating X-ray spectra has been presented in Reference [41].

A)

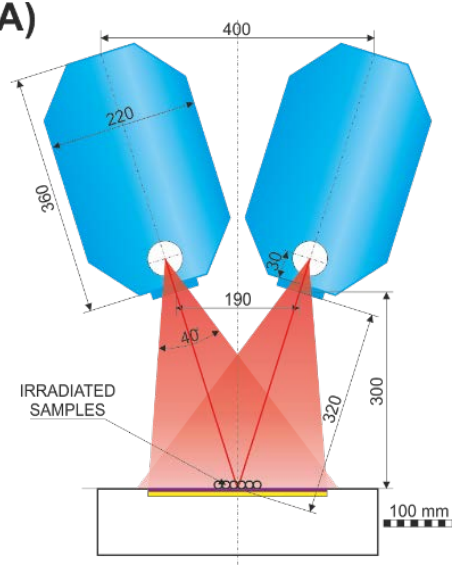

B)

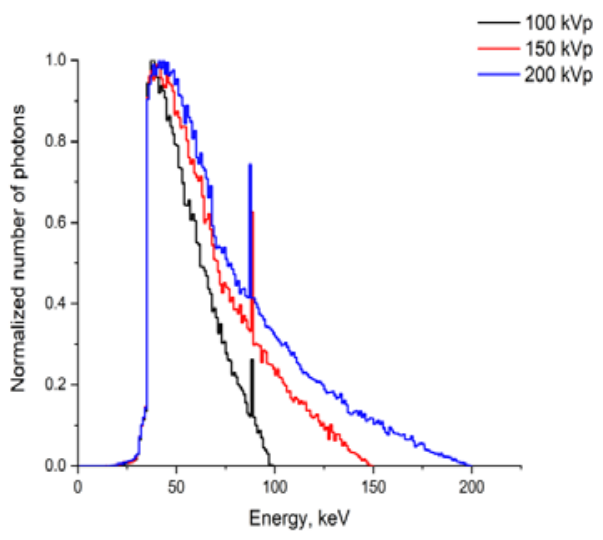

Figure 2. (A) Scheme of irradiation. (B) Spectra of RUST-M1 at various X-ray tubes voltages calculated using Monte-Carlo simulation: $100 \mathrm{kVp}$ (black), $150 \mathrm{kVp}$ (red), and $200 \mathrm{kVp}$ (blue).

DNA samples were centrifuged $(11,000 \mathrm{rpm}, 15 \mathrm{~min})$ immediately after irradiation to remove GNPs. The supernatant was used for electrophoresis in 1\% agarose gel (Tris base-sodium acetate-ethylenediaminetetraacetic acid sodium salt buffer $\mathrm{pH} 8.3,90 \mathrm{~min}$ at $85 \mathrm{kV}$ ). Gels were stained with ethidium bromide (EtBr) and visualized by UV excitation $(\lambda=365 \mathrm{~nm})$. The supercoiled (SC), circular (C), and linear (L) forms of plasmid DNA were detected. Quantitative analysis of electrophoregrams was performed using ImageJ software. Since the fluorescence intensity of EtBr bound to SC DNA is significantly lower than the intensities of EtBr complexes with C and L DNA forms, a correction factor of 1.7 for SC intensity was used [42,43].

SER values were calculated from fitting of the experimental dose-damage curves for the fixed DNA damage effect (i.e., \% SC) by the formula below.

$$
\mathrm{SER}=\frac{D_{\text {count }}}{D_{\mathrm{GNPs}}}
$$

where $D_{\text {cont }}$ is the dose for the observed effect in the control sample without GNPs and $D_{\mathrm{GNPs}}$ is the dose evoking the same effect in the presence of GNPs. The EF values [44] for a given radiation dose were calculated using the formula.

$$
\mathrm{EF}=\frac{\% \mathrm{SC} w / \mathrm{o} \text { GNPs }}{\% \mathrm{SC} \text { with GNPs }}
$$

Physical DEF is defined as the ratio of the dose absorbed by the volume of interest in the presence of GNPs $\left(D_{2}\right)$ to the dose absorbed by the same volume in the absence of GNPs $\left(D_{1}\right)$.

$$
\mathrm{DEF}=\frac{D_{2}}{D_{1}}
$$

If the absorbed dose $D_{1}$ in substance 1 is known, then, under conditions of electronic equilibrium, the absorbed dose $D_{2}$ in substance 2 at the same point of the irradiation field can be calculated by the equation below.

$$
D_{2}=\frac{(\mu / \rho)_{2}}{(\mu / \rho)_{1}} D_{1}
$$

where $(\mu / \rho)_{\mathrm{i}}$ is the photon mass absorption coefficient of the $i$-th substance. In the case of monochromatic radiation and a small volume of interest, the conditions of electronic equilibrium are satisfactory to 
determine the absorbed dose with a $\leq 10 \%$ error. In the case of a polychromatic source, Formula (5) takes the following form.

$$
D_{2}=\frac{\sum_{\mathrm{i}} E_{\mathrm{i}} n_{\mathrm{i}}\left(\frac{\mu\left(E_{\mathrm{i}}\right)}{\rho}\right)_{2}}{\sum_{\mathrm{i}} E_{\mathrm{i}} n_{\mathrm{i}}\left(\frac{\mu\left(E_{i}\right)}{\rho}\right)_{1}} D_{1}=\frac{\overline{\left(\frac{\mu}{\rho}\right)_{2}}}{\overline{\left(\frac{\mu}{\rho}\right)_{1}}} D_{1}=\overline{\left(\frac{\mu}{\rho}\right)_{1}^{2}} D_{1}
$$

In Formula (6), $n_{\mathrm{i}}$ stands for the number of photons with energy $E_{\mathrm{i}}$ and summation is performed over the energies of all photons emitted in the decay (including X-ray radiation due to the electron shell transitions). Thus, we obtain the following expression for DEF.

$$
\mathrm{DEF}=\overline{\left(\frac{\mu}{\rho}\right)_{1}^{2}}
$$

The values of the photon mass absorption coefficients were taken from Reference [45]. For a substance mixed of various chemical elements, the mass absorption coefficient can be calculated by the equation below.

$$
\frac{\mu_{\mathrm{en}}}{\rho}=\sum_{\mathrm{i}} w_{\mathrm{i}}\left(\frac{\mu_{\mathrm{en}}}{\rho}\right)_{\mathrm{i}}
$$

where $\left(\frac{\mu_{\mathrm{en}}}{\rho}\right)_{\mathrm{i}}$ is the energy absorption coefficient of the $i$-th element in the mixture and $w_{\mathrm{i}}$ is the weight fraction of this element in the mixture.

\section{Results and Discussion}

In the present paper, we investigated GNPs radiosensitization in combination with kilovoltage $\mathrm{X}$-ray radiation. Although X-ray RT machines are significantly less frequent than linear accelerators (e.g., according to the International Atomic Energy Agency (IAEA) for 2020: 31 vs. 67 in Sweden, 83 vs. 447 in Russia, 54 vs. 348 in United Kingdom, 7 vs. 3827 in USA [46]), they are in use for the treatment of superficial neoplasms like skin cancer as well as various non-tumor diseases [47]. X-ray radiation sources are also used in brachytherapy and intraoperative RT [48].

Optimization of the use of nano-radiosensitizers for given clinical conditions is critical for therapeutic efficacy of RT [49]. We investigated optimal exposure conditions for given GNPs. One parameter was used as a variable at each step, that is, either GNP concentration or the dose rate, or X-ray tube voltage. When the highest radiosensitization was achieved, the value of the respective parameter was fixed, and the experiment proceeded to the next step.

The plasmid DNA as a target of ionizing radiation is widely used in studies of radio-modifiers including high- $Z$ NPs [9,35,50-52]. This model is convenient for unraveling the physical and physicochemical mechanisms of GNPs radiosensitization and for quantifying the radiation induced damage of bio-macromolecules. As shown in Figure 3, the radiation induced single-stranded (ssb) and double-stranded (dsb) breaks of the initially SC DNA, which led to the formation of C or L forms of DNA, respectively. These topological isomers of DNA can be identified by different electrophoretic mobility in a gel.

The typical electrophoregram of pBR322 DNA exposed to X-ray (0-40 Gy) is shown in Figure 4A. In the non-irradiated sample (lane 0 ) $>95 \%$ of the plasmid DNA is in a SC form. X-ray irradiation led to a dose-dependent decrease in the amount of the SC form and a concomitant increase in the $\mathrm{C}$ form. The $\mathrm{L}$ form is detectable only at doses over $25 \mathrm{~Gy}$ but its amount did not exceed $5 \%$. Plots of dose dependences of the content of SC and C DNA forms are shown in Figure 4B.

Irradiation of the plasmid in the presence of GNPs led to an increase in radiation-induced damage. The dependence of EF on GNP concentration $(d=26 \mathrm{~nm})$ in the range of $0.6-2.4 \mathrm{mg} / \mathrm{mL}$ is shown in Figure 5. Total dose is $5 \mathrm{~Gy}$, the tube voltage is $200 \mathrm{kVp}$, and the $0.2 \mathrm{~Gy} / \mathrm{min}$ dose rate is fixed. The mass ratio of DNA and GNPs ranged from 1:3 to 1:60, i.e., from 0.075 to 1.5 particles per one DNA molecule. 
At these concentrations, GNPs alone did not alter plasmid DNA conformation without radiation (data not shown). EF values increased from $1.09 \pm 0.01$ to $1.37 \pm 0.02$ along with elevated GNP concentration. The shape of the concentration dependence is similar to the one reported earlier [9].

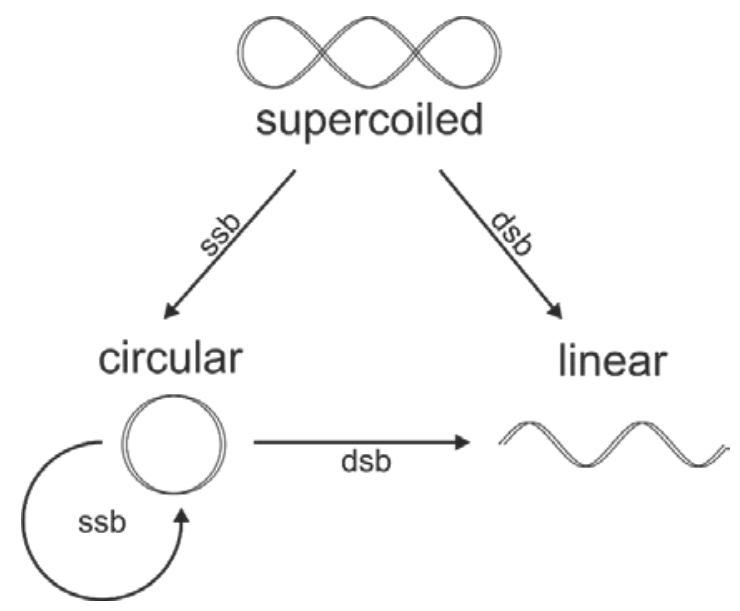

Figure 3. Schematic representation of the radiation induced topological changes in plasmid DNA [42]. The ssb and dsb correspond to single-strand and double-strand breaks, respectively.

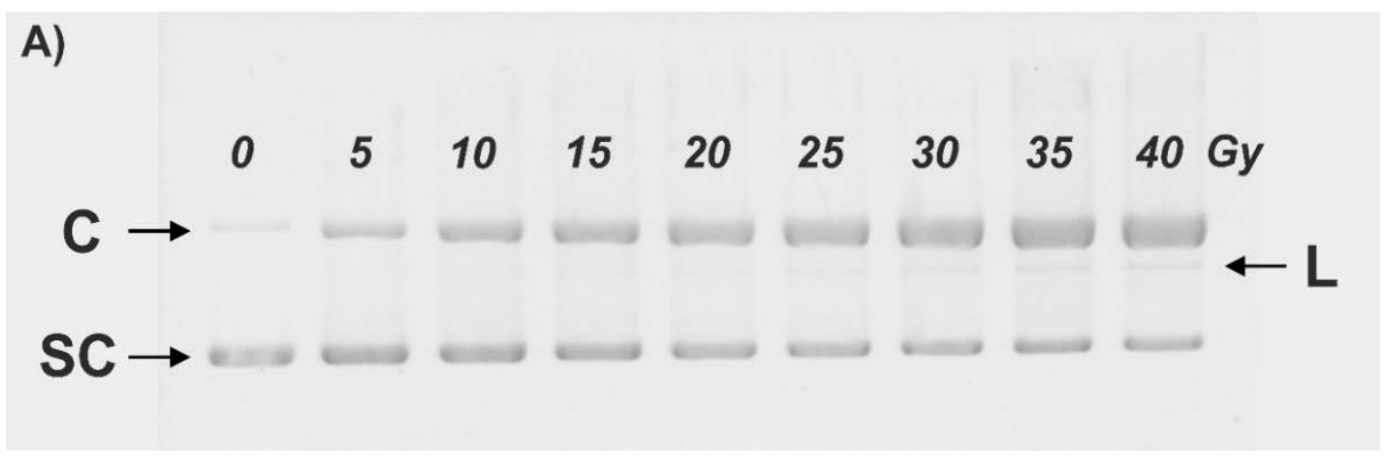

B)

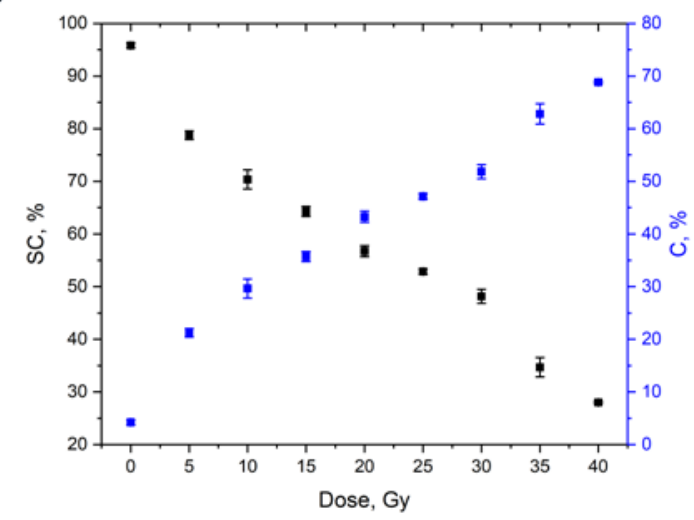

Figure 4. (A) Electrophoregram of pBR322 DNA irradiated with 0-40 Gy. SC, supercoiled. C, circular. L, linear forms. (B) Dependences of the amounts of SC and C forms of pBR322 DNA on the dose of $\mathrm{X}$-ray irradiation. Error bars are mean confidence intervals calculated by three parallel independent measurements for $\alpha=0.05$.

The impact of the radiation dose rate is an underestimated issue in high-Z NPs radiosensitization. Changes in the dose rate noticeably affected the magnitude of radiosensitization by metal and metal oxide NPs [53-55]. The yield of the model reaction of coumarin carboxylic acid hydroxylation under X-ray irradiation was dramatically enhanced in the presence of gold and platinum NPs [53]. In this 
case, for $7 \mathrm{~nm}$ GNPs, an increase in the dose rate from $3.3 \mathrm{~Gy} / \mathrm{min}$ to $20 \mathrm{~Gy} / \mathrm{min}$ led to a several-fold enhancement. At the same time, an increased production of highly fluorescent 7-hydroxycoumarin in the presence of $32.5 \mathrm{~nm}$ GNPs, showing an increase in hydroxyl radicals' production, was observed along with a decrease in the dose rate from $936 \mathrm{~Gy} / \mathrm{min}$ to $36 \mathrm{~Gy} / \mathrm{min}$ [54]. However, the ranges of dose rate values ( $>6-10 \mathrm{~Gy} / \mathrm{min}$ ) investigated in References [53,54] are not widely used in the clinical practice. The effect of the dose rate was even more complex for cell models [55]. The magnitude of radiosensitization by the dextran-coated iron oxide NPs in HeLa and MCF-7 cells rose with the increase in the dose rate from $40 \mathrm{cGy} / \mathrm{min}$ to $370 \mathrm{cGy} / \mathrm{min}$. The maximum effect for HeLa cells was achieved at $370 \mathrm{cGy} / \mathrm{min}$ and $80 \mu \mathrm{g} / \mathrm{mL}$ GNPs whereas irradiation of MCF-7 breast adenocarcinoma cells without NPs gave the same effect at $40 \mathrm{cGy} / \mathrm{min}$. At the same time, the absence of the effect of the dose rate on the yield of radicals in aqueous methanol solutions containing $84 \mathrm{~nm} \mathrm{HfO} \mathrm{NPs}_{2}$ has been shown [56].

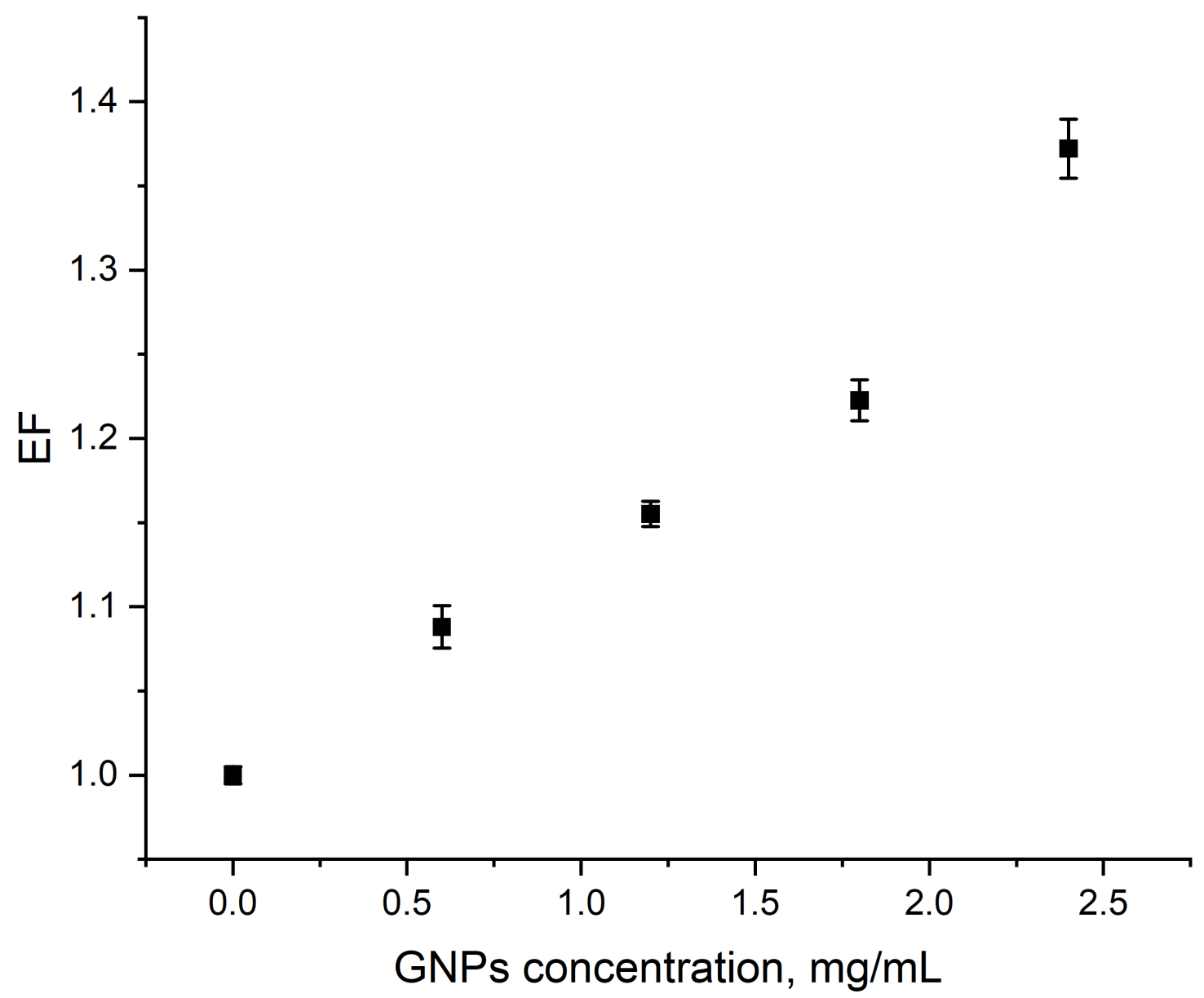

Figure 5. Dependence of enhancement factor (EF) on the concentration of $26 \mathrm{~nm}$ GNPs (5 Gy, $200 \mathrm{kVp}, 0.2 \mathrm{~Gy} / \mathrm{min})$. The GNP:DNA ratio in the samples ranged from 0.075 to 1.5 particles per one DNA molecule. Error bars are mean confidence intervals calculated by three parallel independent measurements for $\alpha=0.05$.

In our experiments, at a fixed dose of $5 \mathrm{~Gy}$ and a voltage of $200 \mathrm{kVp}$, the following dose rates were tested: $0.2 \mathrm{~Gy} / \mathrm{min}, 0.41 \mathrm{~Gy} / \mathrm{min}, 0.85 \mathrm{~Gy} / \mathrm{min}, 1.36 \mathrm{~Gy} / \mathrm{min}$, and $2.1 \mathrm{~Gy} / \mathrm{min}$. This range of the dose rates matches the clinical conditions of external kilovoltage X-ray RT and electronic brachytherapy. The change in the dose rate did not affect DNA damage in the absence of GNPs. In contrast, in the presence of GNPs, a noticeable change in the magnitude of this effect was observed. Figure 6 shows the dependence of EF on the irradiation dose rate for GNP concentrations of $0.6 \mathrm{mg} / \mathrm{mL}$ and $2.4 \mathrm{mg} / \mathrm{mL}$. At $2.1 \mathrm{~Gy} / \mathrm{min}$, which is the highest tested dose rate, $26 \mathrm{~nm}$ GNPs showed the weakest 
effect: $\mathrm{EF}=1.01 \pm 0.01$ and $1.04 \pm 0.01$ at $0.6 \mathrm{mg} / \mathrm{mL}$ and $2.4 \mathrm{mg} / \mathrm{mL}$, respectively. A gradual decrease in the dose rate to $0.2 \mathrm{~Gy} / \mathrm{min}$, similarly to previous results [54], led to an increased DNA damage of $\mathrm{EF}=1.09 \pm 0.02$ and $1.37 \pm 0.02$ at the same GNP concentrations. Thus, in this model, the highest radiosensitization by $26 \mathrm{~nm}$ GNPs was achieved at the lowest dose rate.

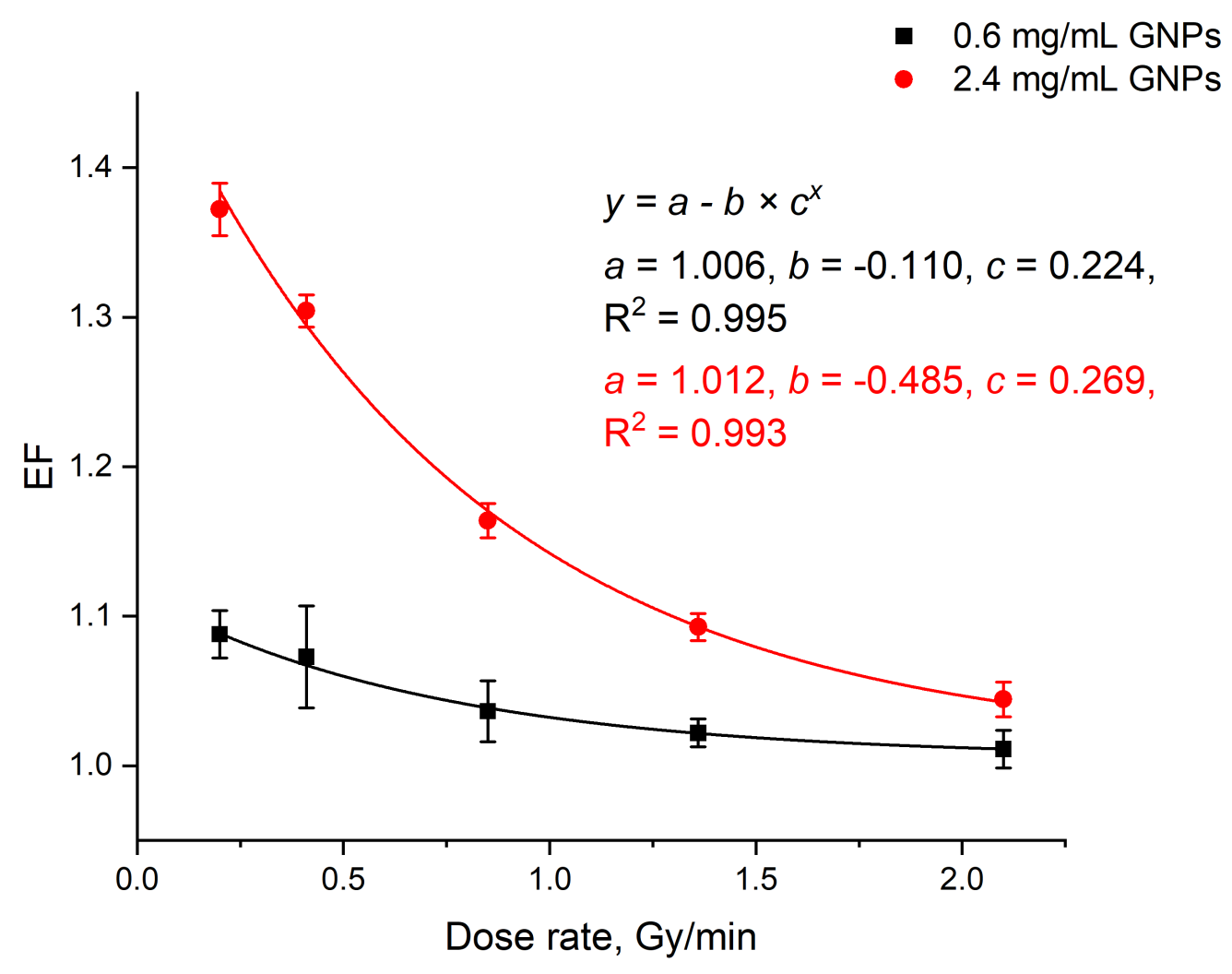

Figure 6. Dependence of EF on the dose rate at $0.6 \mathrm{mg} / \mathrm{mL}$ (black) and $2.4 \mathrm{mg} / \mathrm{mL}$ (red) GNPs ( $\mathrm{d}=26 \mathrm{~nm}$, $5 \mathrm{~Gy}$, and $200 \mathrm{kVp}$ ). Error bars are mean confidence intervals calculated by three parallel independent measurements for $\alpha=0.05$.

The voltage on the X-ray tube may also influence the efficacy of GNPs radiosensitization. The amounts of the SC DNA as a function of the dose in the range of 0 to 20 Gy for 100, 150, and $200 \mathrm{kVp}$ voltage values at a fixed dose rate of $0.2 \mathrm{~Gy} / \mathrm{min}(26 \mathrm{~nm} \mathrm{GNP}, 2.4 \mathrm{mg} / \mathrm{mL}$, i.e., $1.5 \mathrm{GNPs}$ per one DNA molecule) are shown in Figure 7. The control experiments without GNPs shown no statistically significant differences in the damage of plasmid DNA caused by the changes in voltage on the X-ray tube. At the same time, the increase in the voltage on the X-ray tube significantly enhances the GNPs radio-sensitizing effect. Experimental data fitting with the exponential model was carried out according to Reference [57]. Within this model, SER did not depend on the effect magnitude (i.e., fraction of SC form).

Values of SER and EF (Tables 2 and 3) were also calculated by fitting the results using Formulas (2) and (3). The most pronounced radio-sensitization as determined by SER $2.74 \pm 0.61$ was achievable with $2.4 \mathrm{mg} / \mathrm{mL}$ GNPs, $200 \mathrm{kVp}$, and $0.2 \mathrm{~Gy} / \mathrm{min}$ (red curve in Figure 7). 


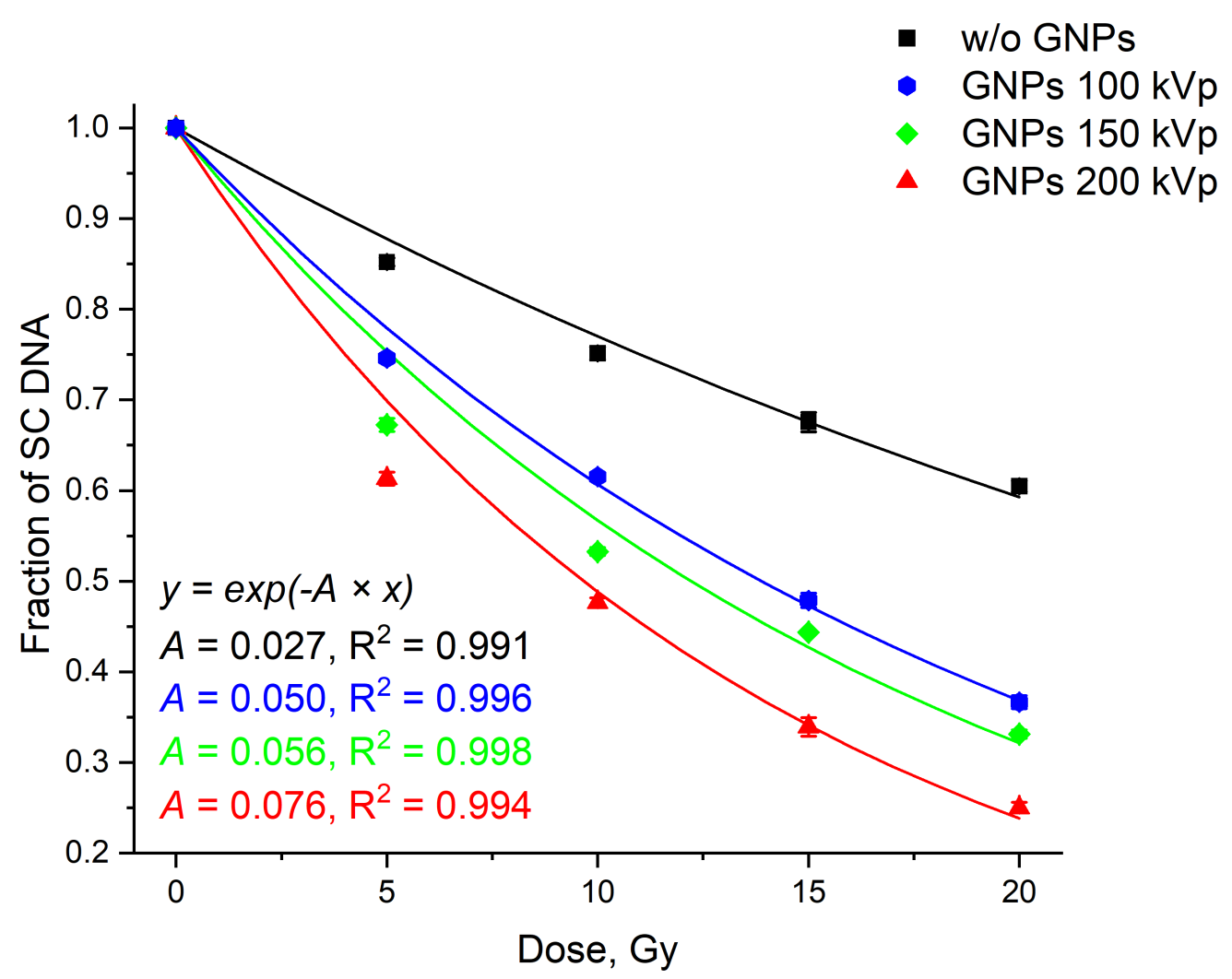

Figure 7. Dependencies of DNA damage on the irradiation dose at a different voltage on the X-ray tube: without GNPs (200 kVp, black) and in the presence of $2.4 \mathrm{mg} / \mathrm{mL}$ GNPs $(\mathrm{d}=26 \mathrm{~nm})$ at $100 \mathrm{kVp}$ (blue), $150 \mathrm{kVp}$ (green), and $200 \mathrm{kVp}$ (red). The GNP:DNA ratio in the samples was 1.5 particles per one DNA molecule. Error bars are mean confidence intervals calculated by three parallel independent measurements for $\alpha=0.05$.

Table 2. EF values for different voltages on the X-ray tube in the presence of $2.4 \mathrm{mg} / \mathrm{mL}$ of $26 \mathrm{~nm}$ GNPs.

\begin{tabular}{cccc}
\hline \multirow{2}{*}{ Dose, Gy } & \multicolumn{3}{c}{ Voltage, $\mathbf{k V p}$} \\
\cline { 2 - 4 } & $\mathbf{1 0 0}$ & $\mathbf{1 5 0}$ & $\mathbf{2 0 0}$ \\
\hline 5 & $1.13 \pm 0.02$ & $1.17 \pm 0.08$ & $1.26 \pm 0.09$ \\
10 & $1.27 \pm 0.04$ & $1.36 \pm 0.09$ & $1.58 \pm 0.10$ \\
15 & $1.43 \pm 0.05$ & $1.58 \pm 0.11$ & $1.98 \pm 0.12$ \\
20 & $1.61 \pm 0.07$ & $1.84 \pm 0.13$ & $2.49 \pm 0.13$ \\
\hline
\end{tabular}

Table 3. Sensitizer enhancement ratio (SER) values for different voltages on the X-ray tube in the presence of $2.4 \mathrm{mg} / \mathrm{mL}$ of $26 \mathrm{~nm}$ GNPs.

\begin{tabular}{ccc}
\hline \multicolumn{3}{c}{ Voltage, $\mathbf{k V p}$} \\
\hline $\mathbf{1 0 0}$ & $\mathbf{1 5 0}$ & $\mathbf{2 0 0}$ \\
\hline $1.91 \pm 0.32$ & $2.17 \pm 0.56$ & $2.74 \pm 0.61$ \\
\hline
\end{tabular}

Next, we studied whether these irradiation conditions are optimal for other sizes of GNPs. The impact of the particle size on the magnitude of radiosensitization by GNPs is known even though the experimental data differ qualitatively. In Reference [9], the larger GNPs gave a greater radiosensitization. However, an increase in the particle size led to an increase in the internal absorption of secondary radiation [20]. Furthermore, 5-nm GNPs gave greater dose enhancement factors of double-strand breaks of DNA than 20-nm particles [50]. Misawa et al. [21] showed that the magnitude of the superoxide radical yield decreased with the increased size of GNPs. 
Figure 8 shows the dose dependencies of the SC fraction after DNA irradiation in the presence of GNPs of various diameters for different X-ray tube voltages and a dose rate of $0.2 \mathrm{~Gy} / \mathrm{min}$. The trend observed for 26-nm GNPs was similar for other particle sizes. The increased voltage led to an increased radiosensitization. The maximal effect was observed at $200 \mathrm{kVp}$. The radiosensitization efficacy also increased with GNP size. The weakest radiosensitization was demonstrated by 12-nm GNPs. The greatest efficiency corresponded to 26-nm GNPs. At $200 \mathrm{kVp}$ voltage, statistically significant differences for 15-nm and 21-nm GNPs were observed only at 15 Gy where 21-nm GNPs showed a slightly higher effect.
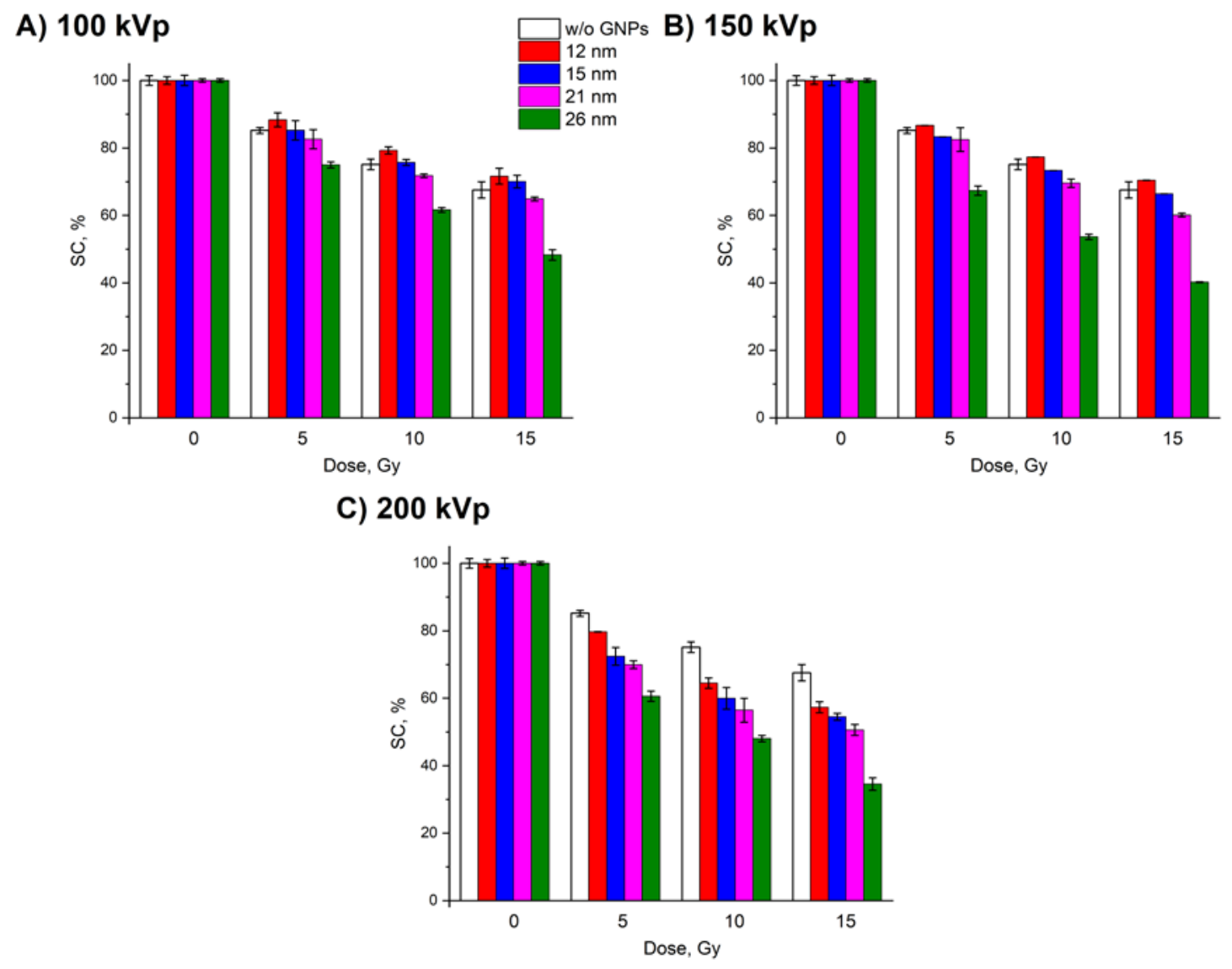

Figure 8. Effect of the X-ray tube voltage on the amount of SC DNA (relative to control samples): $100 \mathrm{kVp}$ (A), $150 \mathrm{kVp}$ (B), and $200 \mathrm{kVp}$ (C). No GNPs (white). $2.4 \mathrm{mg} / \mathrm{mL}$ GNPs with a size of $12 \mathrm{~nm}$ (red), $15 \mathrm{~nm}$ (blue), $21 \mathrm{~nm}$ (magenta), and $26 \mathrm{~nm}$ (green). The GNP:DNA ratios in the samples were $15.3(12 \mathrm{~nm}), 7.8(15 \mathrm{~nm}), 2.8(21 \mathrm{~nm})$, and $1.5(26 \mathrm{~nm})$ particles per one DNA molecule. Error bars are mean confidence intervals calculated by three parallel independent measurements for $\alpha=0.05$.

In the present study, the greatest radiosensitization corresponded to the largest GNP size at a fixed dose rate of $0.2 \mathrm{~Gy} / \mathrm{min}$. However, variation of the dose rate may change this trend. To verify this assumption, we performed, for the first time, systematic experiments on the impact of the dose rate on radiosensitization by GNPs of various sizes (Figure 9). For 12-nm GNPs, an increase in the dose rate from $0.2 \mathrm{~Gy} / \mathrm{min}$ to $2.1 \mathrm{~Gy} / \mathrm{min}$ led to a $\sim 1.13$-fold increased radiosensitization. There were no statistically significant differences in radiosensitization efficacy of 15-nm GNPs along with the dose rate variations from $0.85 \mathrm{~Gy} / \mathrm{min}$ to $2.1 \mathrm{~Gy} / \mathrm{min}$. For 21-nm and 26-nm GNPs, an increased radiosensitization was observed with the decrease in the dose rate from $2.1 \mathrm{~Gy} / \mathrm{min}$ to $0.2 \mathrm{~Gy} / \mathrm{min}$. Thus, when the GNP size increased, the slope of the curve reversed from positive for $12 \mathrm{~nm}$ and $15 \mathrm{~nm}$ GNPs to negative for $21 \mathrm{~nm}$ and $26 \mathrm{~nm}$ GNPs. Thus, at $0.2 \mathrm{~Gy} / \mathrm{min}$ dose rate, the largest $(26 \mathrm{~nm}) \mathrm{GNPs}$ showed the best radiosensitization while $12 \mathrm{~nm}$ and $15 \mathrm{~nm}$ GNPs were the most efficient at $2.0 \mathrm{~Gy} / \mathrm{min}$. Changes in the 
dose, voltage, and GNPs concentration influenced EF values only. The slope of the curves remained the same.

\section{A) $12 \mathrm{~nm}$}

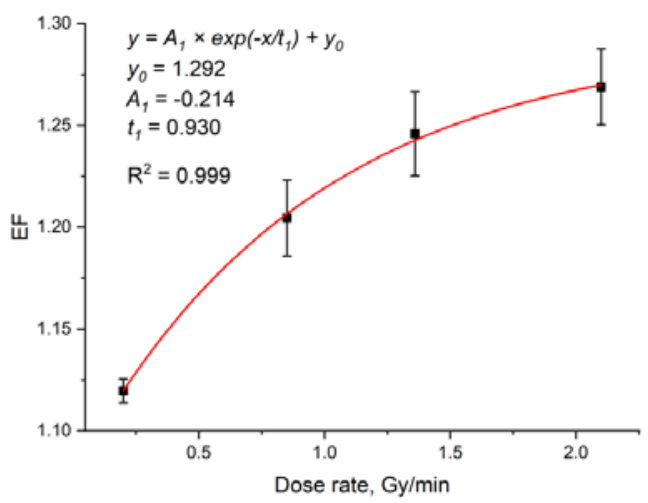

C) $21 \mathrm{~nm}$

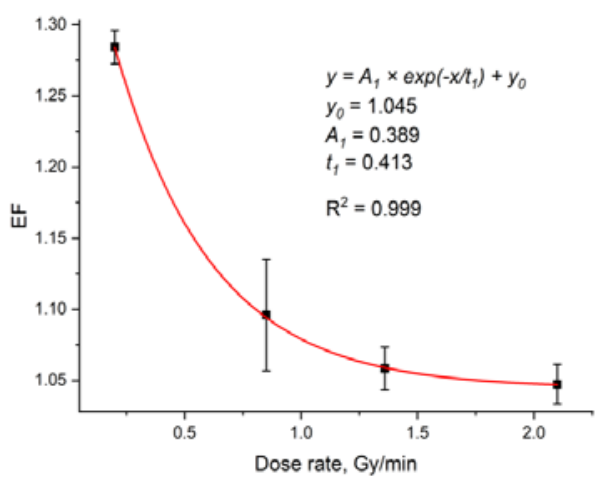

B) $15 \mathrm{~nm}$

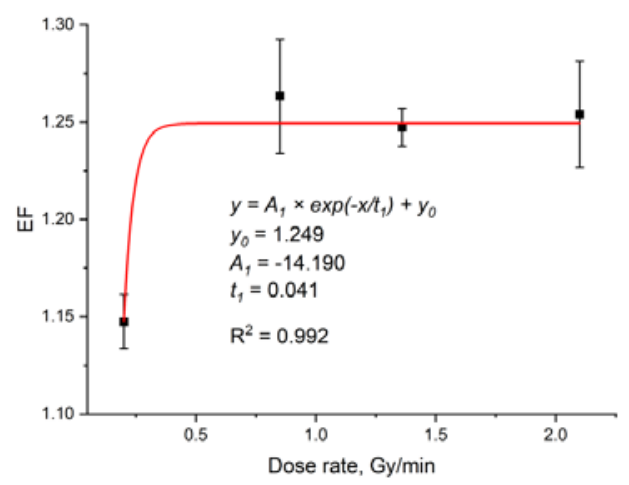

D) $26 \mathrm{~nm}$

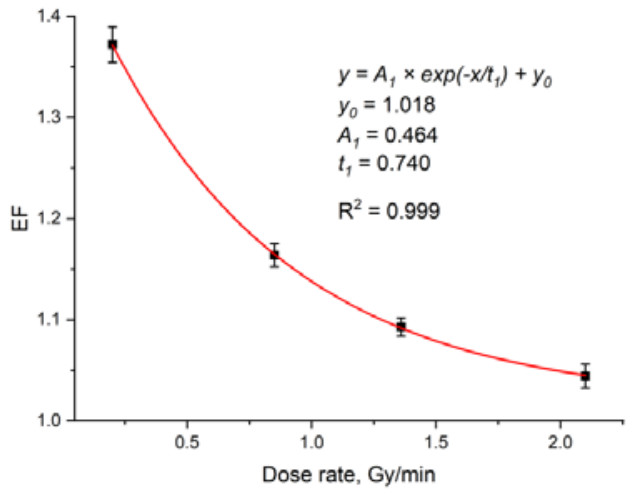

Figure 9. EF as a function of the dose rate for GNPs with a size of $12 \mathrm{~nm}(\mathbf{A}), 15 \mathrm{~nm}(\mathbf{B}), 21 \mathrm{~nm}(\mathbf{C})$, $26 \mathrm{~nm}$ (D) at a fixed dose (5 Gy) and tube voltage (200 kVp). Fitting was performed according to the exponential model. The GNP:DNA ratios in the samples were $15.3(12 \mathrm{~nm}), 7.8(15 \mathrm{~nm}), 2.8(21 \mathrm{~nm})$, and $1.5(26 \mathrm{~nm})$ particles per one DNA molecule. Error bars are mean confidence intervals calculated by three parallel independent measurements for $\alpha=0.05$.

The influence of dose rate on the magnitude of radiosensitization cannot be explained by physical processes alone, but rather has a physicochemical/chemical nature. Clarification of the reasons for this effect is one of our next goals. Nevertheless, it can be assumed that such variability indicates the presence of several mechanisms of the GNPs' radiosensitization depending on the specific conditions of the experiment. In this regard, we note that the multidirectional trends of the radiosensitization effect dependence on dose rate were also observed in References [53,54] (see above). Their authors discussed the different mechanisms of the radio-enhancement effect. According to Reference [50], reactions involving free radicals occur directly on the NP surface and the yield of products strongly depends on the nature of the NP material. At the same time, according to Reference [54], formation of hydroxyl radicals under the radiation exposure occurs in a structured water layer near the GNP surface in which intermolecular hydrogen bonds are lengthened and weakened.

A significant part of experimental studies on high-Z NPs radiosensitization has been performed with X-ray irradiation. Commonly, only the X-ray tube voltage is given whereas data on the anode material, filter characteristics, and the tube spectrum are less available. Nevertheless, the spectral composition of radiation significantly affects radiosensitization by NPs [34,58]. The highest radiosensitization enhancement factor was achieved with a lower X-ray tube voltage: $1.66(105 \mathrm{kVp})$ vs. $1.43(220 \mathrm{kVp})$ [33]. A similar trend was reported in Reference [32]: $24.6(80 \mathrm{kVp})$ vs. $2.2(150 \mathrm{kVp})$. 
Theoretical calculations showed that physical DEF for bismuth, gold, and platinum NPs decreased with the increase in voltage from $50 \mathrm{kVp}$ to $100-300 \mathrm{kVp}$ [59]. On the contrary, we found that voltage increase from $50 \mathrm{kVp}$ to $200 \mathrm{kVp}$ enhanced the radiosensitization.

The magnitude of radiation-induced damage is largely determined by the amount of absorbed photon energy, which depends on the spectral characteristics of the radiation source. We calculated the macroscopic physical increase in the absorbed dose (DEF) for spectra of various X-ray tubes (Table S1) at $200 \mathrm{kVp}$ (Figure 10). For spectra with different effective energies, a significant spread of DEF values was found. The highest calculated DEF $(\sim 1.32)$ value corresponded to the $X$-ray machine used in the present work. For other cases, DEF values varied from $\sim 1.06$ to $\sim 1.23$. We found no function to adequately describe the results for this set of X-ray spectra.

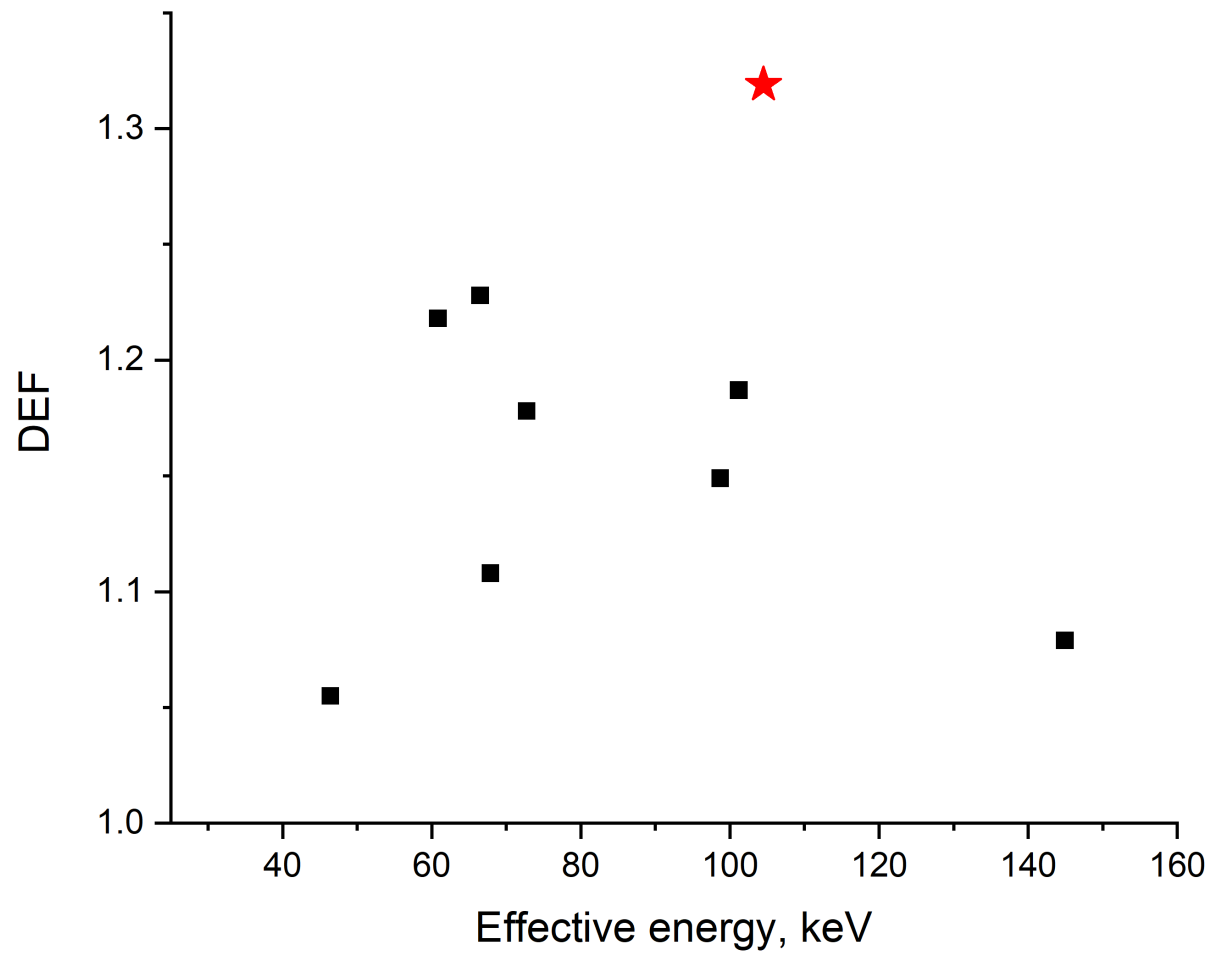

Figure 10. Comparison of calculated physical dose enhancement factor (DEF) for X-ray spectra with various effective energies at a voltage of $200 \mathrm{kVp}$ (black dots, see supplementary files) with DEF for the spectrum of RUST-M1, used in our study (red star).

Thus, direct comparison of radiosensitization efficacies of NPs obtained with X-ray devices with different spectral properties, even at equal voltage on the X-ray tube, is incorrect. The results obtained with individual X-ray units may vary significantly. Given the variety of experimental devices with different spectral composition, data obtained in each case can be essentially unique. At the same time, the types of X-ray machines used in the clinic are limited, which allows us to hope for data unification.

\section{Conclusions}

In the present study, the search for optimal conditions of orthovoltage X-ray exposure to achieve the greatest effect of radiosensitization by GNPs of various sizes was performed. Experiments with radiation-induced damage of the plasmid DNA identified the X-ray tube voltage, dose rate, and particle size as critical parameters of radiosensitization by GNPs. The greatest efficacy was observed for the largest tested GNP size $(26 \mathrm{~nm})$ and the highest voltage $(200 \mathrm{kVp})$. This voltage was found to be optimal for all GNP sizes. However, under a certain dose rate, a more pronounced radiosensitization was detectable for smaller GNPs. Thus, GNPs are an effective tool for increasing the efficacy of the X-ray RT. However, their application requires careful selection of irradiation parameters. 
In the present work, the greatest radiosensitization was demonstrated for $2.4 \mathrm{mg} / \mathrm{mL}$ GNPs. Although the toxicity of GNPs may vary depending on their design and used biological model, the concentration range of gold seems suitable for both cell models and for an in vivo application [60-63].

The results obtained are difficult to extrapolate to more complex biological systems since the relationship between physical and biological effects is extraordinarily complex. Due to the biological response to radiation, the situation may vary significantly. Moreover, although some studies have shown an increase in radiation-induced cellular DNA damage in the presence of NPs [64,65], it was shown that cell death may be due to other mechanisms [66,67].

We also note that in in vitro experiments (and, especially, in vivo), the adsorption of protein molecules (as well as other cell compounds, e.g., glucose, amino acids, etc.) on the GNPs' surface may change the radiosensitization and observed dose rate effect to some extent. Therefore, our further work will be devoted to the complex study of GNPs' radiosensitization on the panel of cellular models using $\mathrm{kV}$ and $\mathrm{MV}$ radiation sources with different irradiation conditions.

Supplementary Materials: The following are available online at http://www.mdpi.com/2079-4991/10/5/952/s1. Figure S1: Normalized spectra calculated using Geant4 for a given set of X-ray tubes. Table S1: Characteristics of X-ray tubes used in the Monte-Carlo simulation.

Author Contributions: Conceptualization, V.N.M., M.A.K., and A.V.B. Methodology, V.N.M., A.A.S., and A.V.B. Software, A.V.B. Validation, M.A.K., A.V.B., and V.M.R. Formal analysis, A.V.B., V.M.R., and A.A.S. Investigation, K.V.M., A.K.I., M.E.K., E.M.S., O.V.D., and M.H.S. Resources, V.M.R. and A.S.S. Writing-original draft preparation, V.N.M. Writing-review and editing, V.N.M., M.A.K., A.V.B., O.V.D., V.M.R., and A.A.S. Visualization, K.V.M., M.E.K., O.V.D., A.V.B., and V.N.M. Supervision, A.S.S. Project administration, V.N.M., M.A.K., and A.S.S. Funding acquisition, A.S.S. All authors have read and agreed to the published version of the manuscript.

Funding: The JSC Science and Innovation of ROSATOM according to the Nuclear Medicine Development program funded the study (AAAA-A19-119122590084-4).

Acknowledgments: The authors are grateful to Nikolay Y. Morozov for help in discussing the results.

Conflicts of Interest: The authors declare no conflict of interest.

\section{References}

1. Moulder, J.E. Chemical radiosensitizers: The Journal history. Int. J. Radiat. Biol. 2019, 95, 940-944. [CrossRef] [PubMed]

2. Linkous, A.G.; Yazlovitskaya, E.M. Novel radiosensitizing anticancer therapeutics. Anticancer Res. 2012, 32, 2487-2499. [PubMed]

3. Wang, H.; Mu, X.; He, H.; Zhang, X.D. Cancer Radiosensitizers. Trends Pharmacol. Sci. 2019, 39, $24-48$. [CrossRef] [PubMed]

4. Gill, M.R.; Vallis, K.A. Transition metal compounds as cancer radiosensitizers. Chem. Soc. Rev. 2019, 48, 540-557. [CrossRef]

5. Su, X.Y.; Liu, P.D.; Wu, H.; Gu, N. Enhancement of radiosensitization by metal-based nanoparticles in cancer radiation therapy. Cancer Biol. Med. 2014, 11, 86-91.

6. Lacombe, S.; Porcel, E.; Scifoni, E. Particle therapy and nanomedicine: State of art and research perspectives. Cancer Nanotechnol. 2017, 8, 9. [CrossRef]

7. Liu, Y.; Zhang, P.; Li, F.; Jin, X.; Li, J.; Chen, W.; Li, Q. Metal-based NanoEnhancers for Future Radiotherapy: Radiosensitizing and Synergistic Effects on Tumor Cells. Theranostics 2018, 8, 1824-1849. [CrossRef]

8. Kuncic, Z.; Lacombe, S. Nanoparticle radio-enhancement: Principles, progress and application to cancer treatment. Phys. Med. Biol. 2018, 63, 02TR01. [CrossRef]

9. Brun, E.; Sanche, L.; Sicard-Roselli, C. Parameters governing gold nanoparticle X-ray radiosensitization of DNA in solution. Colloids Surf. B Biointerfaces 2009, 72, 128-134. [CrossRef]

10. Brun, E.; Duchambon, P.; Blouquit, Y.; Keller, G.; Sanche, L.; Sicard-Roselli, C. Gold nanoparticles enhance the X-ray-induced degradation of human centrin 2 protein. Radiat. Phys. Chem. 2009, 78, 177-183. [CrossRef]

11. Wang, C.; Li, X.; Wang, Y.; Liu, Z.; Fu, L.; Hu, L. Enhancement of radiation effect and increase of apoptosis in lung cancer cells by thio-glucose-bound gold nanoparticles at megavoltage radiation energies. J. Nanoparticle Res. 2013, 15, 1642. [CrossRef] 
12. Kim, E.H.; Kim, M.S.; Song, H.S.; Yoo, S.H.; Sai, S.; Chung, K.; Sung, J.; Jeong, Y.K.; Jo, Y.; Yoon, M. Gold nanoparticles as a potent radiosensitizer in neutron therapy. Oncotarget 2017, 8, 112390-112400. [CrossRef] [PubMed]

13. Hainfeld, J.F.; Dilmanian, F.A.; Zhong, Z.; Slatkin, D.N.; Kalef-Ezra, J.A.; Smilowitz, H.M. Gold nanoparticles enhance the radiation therapy of a murine squamous cell carcinoma. Phys. Med. Biol. 2010, 55, 3045-3059. [CrossRef] [PubMed]

14. Geng, F.; Xing, J.Z.; Chen, J.; Yang, R.; Hao, Y.; Song, K.; Kong, B. Pegylated glucose gold nanoparticles for improved in-vivo bio-distribution and enhanced radiotherapy on cervical cancer. J. Biomed. Nanotechnol. 2014, 10, 1205-1216. [CrossRef]

15. Grzelczak, M.; Pérez-Juste, J.; Mulvaney, P.; Liz-Marzán, L.M. Shape control in gold nanoparticle synthesis. Chem. Soc. Rev. 2008, 37, 1783-1791. [CrossRef]

16. Sperling, R.A.; Parak, W.J. Surface modification, functionalization and bioconjugation of colloidal inorganic nanoparticles. Philos. Trans. A Math. Phys. Eng. Sci. 2010, 368, 1333-1383. [CrossRef]

17. Dykman, L.; Khlebtsov, N. Gold nanoparticles in biomedical applications: Recent advances and perspectives. Chem. Soc. Rev. 2012, 41, 2256-2282. [CrossRef]

18. Jiang, Y.; Huo, S.; Mizuhara, T.; Das, R.; Lee, Y.W.; Hou, S.; Moyano, D.F.; Duncan, B.; Liang, X.J.; Rotello, V.M. The Interplay of Size and Surface Functionality on the Cellular Uptake of Sub-10 nm Gold Nanoparticles. ACS Nano 2015, 9, 9986-9993. [CrossRef]

19. Xie, X.; Liao, J.; Shao, X.; Li, Q.; Lin, Y. The Effect of shape on Cellular Uptake of Gold Nanoparticles in the forms of Stars, Rods, and Triangles. Sci. Rep. 2017, 7, 3827. [CrossRef]

20. Lechtman, E.; Chattopadhyay, N.; Cai, Z.; Mashouf, S.; Reilly, R.; Pignol, J.P. Implications on clinical scenario of gold nanoparticle radiosensitization in regards to photon energy, nanoparticle size, concentration and location. Phys. Med. Biol. 2011, 56, 4631-4647. [CrossRef]

21. Misawa, M.; Takahashi, J. Generation of reactive oxygen species induced by gold nanoparticles under x-ray and UV Irradiations. Nanomedicine 2011, 7, 604-614. [CrossRef] [PubMed]

22. Gilles, M.; Brun, E.; Sicard-Roselli, C. Gold nanoparticles functionalization notably decreases radiosensitization through hydroxyl radical production under ionizing radiation. Colloids Surf. B Biointerfaces 2014, 123, 770-777. [CrossRef] [PubMed]

23. Spaas, C.; Dok, R.; Deschaume, O.; De Roo, B.; Vervaele, M.; Seo, J.W.; Bartic, C.; Hoet, P.; Van den Heuvel, F.; Nuyts, S.; et al. Dependence of Gold Nanoparticle Radiosensitization on Functionalizing Layer Thickness. Radiat. Res. 2016, 185, 384-392. [CrossRef] [PubMed]

24. Belousov, A.V.; Morozov, V.N.; Krusanov, G.A.; Kolyvanova, M.A.; Chernyaev, A.P.; Shtil, A.A. Modeling the Effect of Surface Modification of Gold Nanoparticles Irradiated with ${ }^{60}$ Co on the Secondary Particles Emission Spectrum. Dokl. Phys. 2018, 63, 96-99. [CrossRef]

25. Belousov, A.V.; Morozov, V.N.; Krusanov, G.A.; Kolyvanova, M.A.; Chernyaev, A.P.; Shtil, A.A. Spectra of secondary particles generated upon virtual irradiation of gold nanosensitizers: Implications for surface modification. Biomed. Phys. Eng. Express 2018, 4, 045023. [CrossRef]

26. Belousov, A.V.; Morozov, V.N.; Krusanov, G.A.; Kolyvanova, M.A.; Shtil, A.A. The Effect of Gold Nanoparticle Surface Modification with Polyethylene Glycol on the Absorbed Dose Distribution upon Irradiation with ${ }^{137} \mathrm{Cs}$ and ${ }^{60}$ Co Photons. Biophysics 2019, 64, 23-30. [CrossRef]

27. Butterworth, K.T.; Coulter, J.A.; Jain, S.; Forker, J.; McMahon, S.J.; Schettino, G.; Prise, K.M.; Currell, F.J.; Hirst, D.G. Evaluation of cytotoxicity and radiation enhancement using $1.9 \mathrm{~nm}$ gold particles: Potential application for cancer therapy. Nanotechnology 2010, 21, 295101. [CrossRef]

28. Zhang, X.D.; Wu, D.; Shen, X.; Chen, J.; Sun, Y.M.; Liu, P.X.; Liang, X.J. Size-dependent radiosensitization of PEG-coated gold nanoparticles for cancer radiation therapy. Biomaterials 2012, 33, 6408-6419. [CrossRef]

29. Marill, J.; Anesary, N.M.; Zhang, P.; Vivet, S.; Borghi, E.; Levy, L.; Pottier, A. Hafnium oxide nanoparticles: Toward an in vitro predictive biological effect? Radiat. Oncol. 2014, 9, 150. [CrossRef]

30. Ma, N.; Wu, F.G.; Zhang, X.; Jiang, Y.W.; Jia, H.R.; Wang, H.Y.; Li, Y.H.; Liu, P.; Gu, N.; Chen, Z Shape-Dependent Radiosensitization Effect of Gold Nanostructures in Cancer Radiotherapy: Comparison of Gold Nanoparticles, Nanospikes, and Nanorods. ACS Appl. Mater. Interfaces 2017, 9, 13037-13048. [CrossRef]

31. Her, S.; Jaffray, D.A.; Allen, C. Gold nanoparticles for applications in cancer radiotherapy: Mechanisms and recent advancements. Adv. Drug Deliv. Rev. 2017, 109, 84-101. [CrossRef] [PubMed] 
32. Rahman, W.N.; Bishara, N.; Ackerly, T.; Fa, C.; Jackson, P.; Wong, C.; Davidson, R.; Geso, M. Enhancement of radiation effects by gold nanoparticles for superficial radiation therapy. Nanomedicine 2009, 5, 136-142. [CrossRef] [PubMed]

33. Chithrani, D.B.; Jelveh, S.; Jalali, F.; van Prooijen, M.; Allen, C.; Bristow, R.G.; Hill, R.P.; Jaffray, D.A. Gold Nanoparticles as Radiation Sensitizers in Cancer Therapy. Radiat. Res. 2010, 173, 719-728. [CrossRef] [PubMed]

34. Roeske, J.C.; Nunez, L.; Hoggarth, M.; Labay, E.; Weichselbaum, R.R. Characterization of the theoretical radiation dose enhancement from nanoparticles. Technol. Cancer Res. Treat 2007, 6, 395-401. [CrossRef]

35. McMahon, S.J.; Hyland, W.B.; Brun, E.; Butterworth, K.T.; Coulter, J.A.; Douki, T.; Hirst, D.G.; Jain, S.; Kavanagh, A.P.; Krpetic, Z.; et al. Energy Dependence of Gold Nanoparticle Radiosensitization in Plasmid DNA. J. Phys. Chem. C 2011, 115, 20160-20167. [CrossRef]

36. Rahman, W.N.; Corde, S.; Yagi, N.; Abdul Aziz, S.A.; Annabell, N.; Geso, M. Optimal energy for cell radiosensitivity enhancement by gold nanoparticles using synchrotron-based monoenergetic photon beams. Int. J. Nanomed. 2014, 9, 2459-2467. [CrossRef]

37. Bastús, N.G.; Comenge, J.; Puntes, V. Kinetically controlled seeded growth synthesis of citrate-stabilized gold nanoparticles of up to $200 \mathrm{~nm}$ : Size focusing versus Ostwald ripening. Langmuir 2011, 27, 11098-11105. [CrossRef]

38. Edgar, J.A.; McDonagh, A.M.; Cortie, M.B. Formation of Gold Nanorods by a Stochastic “Popcorn” Mechanism. ACS Nano 2012, 6, 1116-1125. [CrossRef]

39. Prado-Gotora, R.; Grueso, E. A kinetic study of the interaction of DNA with gold nanoparticles: Mechanistic aspects of the interaction. Phys. Chem. Chem. Phys. 2011, 13, 1479-1489. [CrossRef]

40. Allison, J.; Amako, K.; Apostolakis, J.; Arce, P.; Asai, F.; Aso, T.; Bagli, E.; Bagulya, A.; Banerjee, S.; Barrand, G.; et al. Recent developments in Geant4. Nucl. Instrum. Methods Phys. Res. A 2016, 32, 1187-1200. [CrossRef]

41. Belousov, A.V.; Bliznyuk, U.A.; Borschegovskaya, P.Y.; Osipov, A.S. The biological effectiveness of X-ray radiation. Mosc. Univ. Phys. Bull. 2014, 2, 55-59. [CrossRef]

42. Spotheim-Maurizot, M.; Charlier, M.; Sabattier, R. DNA radiolysis by fast neutrons. Int. J. Radiat. Biol. 1990, 57, 301-313. [CrossRef] [PubMed]

43. Stankus, A.A.; Xapsos, M.A.; Kolanko, C.J.; Gerstenberg, H.M.; Blakely, W.F. Energy deposition events produced by fission neutrons in aqueous solutions of plasmid DNA. Int. J. Radiat. Biol. 1995, 68, 1-9. [CrossRef] [PubMed]

44. Retif, P.; Pinel, S.; Toussaint, M.; Frochot, C.; Chouikrat, R.; Bastogne, T.; Barberi-Heyob, M. Nanoparticles for Radiation Therapy Enhancement: The Key Parameters. Theranostics 2015, 5, 1030-1044. [CrossRef] [PubMed]

45. Hubbell, J.H.; Seltzer, S.M. Tables of X-ray Mass Attenuation Coefficients and Mass Energy-Absorption Coefficients from $1 \mathrm{keV}$ to $20 \mathrm{MeV}$ for Elements $\mathrm{Z}=1$ to 92 and 48 Additional Substances of Dosimetric Interest. Natl. Inst. Stand. Technol. 1996. Available online: http://www.nist.gov/pml/data/xraycoef/ (accessed on 24 February 2020).

46. DIRAC (DIrectory of RAdiotherapy Centres) Database-IAEA (International Atomic Energy Agency). Available online: https://dirac.iaea.org/Query/Countries (accessed on 1 May 2020).

47. Seegenschmiedt, M.H.; Micke, O.; Muecke, R.; German Cooperative Group on Radiotherapy for Non-malignant Diseases (GCG-BD). Radiotherapy for non-malignant disorders: State of the art and update of the evidence-based practice guidelines. Br. J. Radiol. 2015, 88, 20150080. [CrossRef] [PubMed]

48. Eaton, D.J. Electronic brachytherapy-Current status and future directions. Br. J. Radiol. 2015, 88, 20150002. [CrossRef]

49. Cui, L.; Her, S.; Borst, G.R.; Bristow, R.G.; Jaffray, D.A.; Allen, C. Radiosensitization by gold nanoparticles: Will they ever make it to the clinic? Radiother. Oncol. 2017, 124, 344-356. [CrossRef]

50. Butterworth, K.T.; Wyer, J.A.; Brennan-Fournet, M.; Latimer, C.J.; Shah, M.B.; Currell, F.J.; Hirst, D.G. Variation of strand break yield for plasmid DNA irradiated with high-Z metal nanoparticles. Radiat. Res. 2008, 170, 381-387. [CrossRef]

51. Xiao, F.; Zheng, Y.; Cloutier, P.; He, Y.; Hunting, D.; Sanche, L. On the role of low-energy electrons in the radiosensitization of DNA by gold nanoparticles. Nanotechnology 2011, 22, 465101. [CrossRef]

52. Schlathölter, T.; Eustache, P.; Porcel, E.; Salado, D.; Štefančíková, L.; Tillement, O.; Lux, F.; Mowat, P.; Biegun, A.K.; van Goethem, M.J.; et al. Improving proton therapy by metal-containing nanoparticles: Nanoscale insights. Int. J. Nanomed. 2016, 11, 1549-1556. [CrossRef] 
53. Cheng, N.N.; Starkewolf, Z.; Davidson, R.A.; Sharmah, A.; Lee, C.; Lien, J.; Guo, T. Chemical enhancement by nanomaterials under X-ray irradiation. J. Am. Chem. Soc. 2012, 134, 1950-1953. [CrossRef] [PubMed]

54. Sicard-Roselli, C.; Brun, E.; Gilles, M.; Baldacchino, G.; Kelsey, C.; McQuaid, H.; Polin, C.; Wardlow, N.; Currell, F. A new mechanism for hydroxyl radical production in irradiated nanoparticle solutions. Small 2014, 10, 3338-3346. [CrossRef]

55. Khoshgard, K.; Kiani, P.; Haghparast, A.; Hosseinzadeh, L.; Eivazi, M.T. Radiation dose rate affects the radiosensitization of MCF-7 and HeLa cell lines to X-rays induced by dextran-coated iron oxide nanoparticles. Int. J. Radiat. Biol. 2017, 93, 757-763. [CrossRef]

56. Shiryaeva, E.S.; Baranova, I.A.; Kiselev, G.O.; Morozov, V.N.; Belousov, A.V.; Sherstiuk, A.A.; Kolyvanova, M.A.; Krivoshapkin, P.V.; Feldman, V.I. Hafnium Oxide as a Nanoradiosensitizer under X-ray Irradiation of Aqueous Organic Systems: A Model Study Using the Spin-Trapping Technique and Monte Carlo Simulations. J. Phys. Chem. C 2019, 123, 27375-27384. [CrossRef]

57. McMahon, S.J.; Currell, F.J. A robust curve-fitting procedure for the analysis of plasmid DNA strand break data from gel electrophoresis. Radiat. Res. 2011, 175, 797-805. [CrossRef] [PubMed]

58. Tsiamas, P.; Liu, B.; Cifter, F.; Ngwa, W.F.; Berbeco, R.I.; Kappas, C.; Theodorou, K.; Marcus, K.; Makrigiorgos, M.G.; Sajo, E.; et al. Impact of beam quality on megavoltage radiotherapy treatment techniques utilizing gold nanoparticles for dose enhancement. Phys. Med. Biol. 2013, 58, 451-464. [CrossRef] [PubMed]

59. Hossain, M.; Su, M. Nanoparticle location and material dependent dose enhancement in X-ray radiation therapy. J. Phys. Chem. C 2012, 116, 23047-23052. [CrossRef]

60. Hainfeld, J.F.; Slatkin, D.N.; Smilowitz, H.M. The use of gold nanoparticles to enhance radiotherapy in mice. Phys. Med. Biol. 2004, 49, N309-N315. [CrossRef]

61. Coulter, J.A.; Jain, S.; Butterworth, K.T.; Taggart, L.E.; Dickson, G.R.; McMahon, S.J.; Hyland, W.B.; Muir, M.F.; Trainor, C.; Hounsell, A.R.; et al. Cell type-dependent uptake, localization, and cytotoxicity of $1.9 \mathrm{~nm}$ gold nanoparticles. Int. J. Nanomed. 2012, 7, 2673-2685. [CrossRef]

62. Chattopadhyay, N.; Cai, Z.; Kwon, Y.L.; Lechtman, E.; Pignol, J.P.; Reilly, R.M. Molecularly targeted gold nanoparticles enhance the radiation response of breast cancer cells and tumor xenografts to X-radiation. Breast Cancer Res. Treat 2013, 137, 81-91. [CrossRef]

63. Bobyk, L.; Edouard, M.; Deman, P.; Vautrin, M.; Pernet-Gallay, K.; Delaroche, J.; Adam, J.F.; Estève, F.; Ravanat, J.L.; Elleaume, H. Photoactivation of gold nanoparticles for glioma treatment. Nanomedicine 2013, 9, 1089-1097. [CrossRef] [PubMed]

64. Mowat, P.; Mignot, A.; Rima, W.; Lux, F.; Tillement, O.; Roulin, C.; Dutreix, M.; Bechet, D.; Huger, S.; Humbert, L.; et al. In vitro radiosensitizing effects of ultrasmall gadolinium based particles on tumour cells. J. Nanosci. Nanotechnol. 2011, 11, 7833-7839. [CrossRef] [PubMed]

65. Miladi, I.; Aloy, M.T.; Armandy, E.; Mowat, P.; Kryza, D.; Magné, N.; Tillement, O.; Lux, F.; Billotey, C.; Janier, M.; et al. Combining ultrasmall gadolinium-based nanoparticles with photon irradiation overcomes radioresistance of head and neck squamous cell carcinoma. Nanomedicine 2015, 11, 247-257. [CrossRef] [PubMed]

66. Štefančíková, L.; Lacombe, S.; Salado, D.; Porcel, E.; Pagáčová, E.; Tillement, O.; Lux, F.; Depeš, D.; Kozubek, S.; Falk, M. Effect of gadolinium-based nanoparticles on nuclear DNA damage and repair in glioblastoma tumor cells. J. Nanobiotechnol. 2016, 14, 63. [CrossRef]

67. Pagáčová, E.; Štefančíková, L.; Schmidt-Kaler, F.; Hildenbrand, G.; Vičar, T.; Depeš, D.; Lee, J.H.; Bestvater, F.; Lacombe, S.; Porcel, E.; et al. Challenges and Contradictions of Metal Nano-Particle Applications for Radio-Sensitivity Enhancement in Cancer Therapy. Int. J. Mol. Sci. 2019, 20, 588. [CrossRef]

(C) 2020 by the authors. Licensee MDPI, Basel, Switzerland. This article is an open access article distributed under the terms and conditions of the Creative Commons Attribution (CC BY) license (http://creativecommons.org/licenses/by/4.0/). 